\title{
TEMPO E NARRATIVA
}

\author{
Maria da Glória Bordini*
}

SÍNTESE - A palestra versa sobre a noção de tempo na antigüidade clássica e na modernidade e sua presença na narrativa literária, explorando as posições de Aristóteles e Paul Ricoeur sobre o modo como o discurso poético organiza o tempo físico. Para tanto, parte do modo fundamental de registro do tempo: o histórico, apoiado na experiência e na memória e secundado pelos sistemas sígnicos e pelos aparelhos ideológicos, e examina as transformações que a concepção de tempo sofre ao integrar uma narrativa literária nos seus dois planos compositivos: 0 da fábula e o do enredo. São utilizados como textos-modelo fragmentos de um episódio da Mlíada, de Homero e de um capitulo do Ulisses, de Joyce.

\begin{abstract}
Time in classical antiquity and in modernity and its presence in the literary narrative is discussed on the basis of Aristotelian poetics and of Paul Ricoeur's theories on how the poetic discourse organizes physical time. The essay starts with the fundamental way of registering time: the historiçal, dealing with experience and memory translated into sign systems and ideological apparatuses, and examines the changes that notions of time undergo when they enter into the two compositional plans of a literary narrative: story and plot. These changes are compared in one fragment of Homer's Miad and of Joyce's Ulisses.
\end{abstract}

O tempo impregna toda a experiência e não pode ser pensado sem sua relação inerente com o espaço e com a consciência humana. Como diz Meyerhoff, "a florescente e ruidosa confusão da experiência parece transmitir a consciência imediata de que uns elementos sucedem a outros, mudam ou perduram". ${ }^{1}$ Daí, a constituição imanente da categoria temporal para o eu, porque na interioridade tudo flui, mas o que é impossível conceber no espaço, como a coincidência de dois pontos no mesmo lugar, ali ocorre sem problemas. Como num acorde musical, o eu pode ter consciência, no mesmo instante, de uma percepção - a escuridão lá fora, de uma emoção - a curiosidade aqui dentro, de uma idéia - a de que o tempo é correlativo do sujeito, ou de uma decisão - vamos seguir em frente. Também como numa sinfonia, podem-se ter séries justapostas, intercruzadas ou interpoladas de momentos vividos, e/ou lembrados e/ou esperados de diferentes ordens, assim como pode-se prolongar-lhes as reverberações ou abafá-las.

Todos esses fenômenos da consciência interna do tempo pertencem-lhe constitutivamente, embora se possa questionar se derivam de uma estrutura mental própria do homem ou se vêm do acúmulo de experiências decorrentes de um mun-

\footnotetext{
* Pontificia Universidade Católica do Rio Grande do Sul, PUCRS

1 MEYERHOFF, Hans. O tempo na literatura. São Paulo: McGraw-Hill do Brasil, 1976. p. 1.
}

\begin{tabular}{|l|l|l|l|l|l|}
\hline VERITAS & Porto Alegre & v. 41 & $\mathrm{n}^{\circ} 162$ & Junho 1996 & p. 339-347 \\
\hline
\end{tabular}


do cósmico e social em permanente movimento e mutação, ou, ainda, da interação da consciência com a realidade. A ciência se inclina a construir uma concepção de tempo não subjetivo, aquilo que na Física se indica com o símbolo "t" e que, no cotidiano social, é marcado com relógios e calendários, um tempo público, que desborda as experiências individuais e as coordena como uma grade que a natureza impusesse sobre essas miríades de vivências internas de tempo. Discute-se se esse tempo objetivo tem mesmo existência ou é uma projeção da consciência, submetida a operações lógicas que a desvestem de suas qualidades de vivência, assim como se indaga se o movimento das partículas fundamentais do átomo são a sede da noção de tempo que persegue os seres animados, votando-os à morte e os dotados de pensamento, endereçando-os à angústia da finitude.

Para Bergson, o tempo é movimento, contínua renovação e transformação da vida, opondo-se ao peso da matéria, que busca submetê-la à inércia do inanimado. Está-se sempre no presente e tem-se noção de sucessão graças à consciência simbolizadora, que trabalha imaginativa e mnemonicamente o instante. Diz ele: "Para nós, não há jamais coisa alguma senão o instantâneo. No que designamos com esse nome já entra um trabalho de nossa memória e, por conseguinte, de nossa consciência que prolonga uns nos outros, de tal forma que os captamos em uma intuição relativamente simples, momentos tão numerosos quanto se queira de um tempo indefinidamente divisivel. ${ }^{2}$

A sucessão dos instantes é, pois, homogeneizada numa sensação de continuidade pelas operações da consciência viva. $\mathrm{O}$ instante é retido entre a memória e a expectativa, pela qualidade de sua vivência, que supera sua descontinuidade e permite ao homem pensá-lo como antecedido e sucedido, mas não sozinho. As mudanças qualitativas, interpenetrando-se, possibilitam a noção de tempo como um meio fluido onde tudo ocorre e pode ser localizado, mas também onde tudo se comunica, sem divisões.

O paradoxo entre a visão existencial e a abordagem científica da categoria do tempo reside aí: também para a construção de um conceito de tempo físico, há que mobilizarem-se instrumentos conceituais humanos, tais como os de mensuração, ordenação e direcionamento. Para vencer a subjetividade das medidas, a Humanidade recorreu aos movimentos periódicos da Natureza, como os dos astros, independentes da vontade humana. Para ver o tempo sem o desejo de homogeneizá-lo, considera-o como pontos no espaço, sucedendo-se numa ordem de causaefeito irreversivel: a da água fervendo sob o calor, por exemplo. Para compreender a sucessão, utiliza as marcas ou registros naturais ou sociais concretos do que ocorreu, para demonstrar a dimensão do passado, em oposição à falta de traços da dimensão do futuro.

Mesmo que o tempo não seja uma ilusão, como queria Zenão de Eléia ao contar a fábula da flecha de Aquiles e da tartaruga, existe o conflito entre o tempo medido e o tempo vivido e é dele que a narrativa se nutre. Já Santo Agostinho percebia as contradições entre viver o presente e construir uma imagem do passado ou do futuro a partir do agora. Afinal, o passado é uma recordação no agora, assim como o futuro é uma antecipação no agora, dependendo ambos das faculdades da

2 BERGSON, Henni. Memonia y vida. Textos escojidos por Gilles Deleuze. Madrid: Alianza, 1987. p. 34. 
memória e da expectativa. Equacionar o tempo enquanto vivência da consciência e enquanto construção lógica de validade objetiva era o seu problema: "O que, então, é o tempo? Se ninguém me pergunta, eu o sei; se desejo explicá-lo àquele que pergunta, não o sei". ${ }^{3}$

Para traduzir os dilemas do tempo na linguagem, existe a forma narrativa, cuja característica principal é dar conta da dimensão cronológica e da dimensão psicológica dos sucessos simultaneamente, espelhando todas as suas possíveis contradições. A substância da narrativa é o tempo antropológico, ou seja, a história como sucessão de acontecimentos para alguma consciência. Embora a palavra história possa ser aplicada à Natureza, para designar as mutações dos seres animados e até inanimados, como um estrato geológico, por exemplo, convém lembrar que é um ser humano que registra esses estágios de transformação e é ele também que os coloca em algum tipo de ordem, a qual vem sempre impregnada de seus interesses.

A capacidade da palavra de abstrair-se da coisa nomeada e atuar num meio sócio-mental, representando-a por convenção, permite às espécies falantes afastarse do concretamente vivido, separar-se do caos das representações sensiveis, fixar as recordações fugidias e os desejos vagos e instituir a ordem, a sucessão e as associações lógicas e afetivas que darão ao tempo vivido a sua consistência e seu sentido, não só na imanência da consciência, mas na convivência social. Daí o nascimento das histórias, como formas lingüísticas de preservar a sabedoria adquirida na vida, realçar certos momentos mais pelo desejo do que pela objetividade, comunicar os saberes e harmonizar o tecido confuso do vivido pela distância protetora dos pontos de observação, pela sedução melódica e rítmica das entonações, timbres de voz, cadências, pausas, acelerações e retardamentos, pela possibilidade de extrair dos casos uma compreensão maior da existência.

Desde as narrativas mais primitivas, encontradas nos mitos, até as mais intelectualmente sofisticadas, como as da literatura moderna e contemporânea, o poder de capturar o tempo nas malhas da linguagem consagra a narrativa como o meio mais eficiente de lidar com todos os aspectos da vivência temporal, sem ficar-se preso a seus paradoxos. Na narrativa, tanto a matéria - os atos e a as situações - quanto a forma - as diversas modalidades de narrar - dão conta da mutação e do movimento do vivido e convocam todas as faculdades envolvidas na experiência temporal de forma mais nítida, porque objetivada nas palavras em sucessão. Poder-se-ia dizer que a narrativa é a mímese da vivência temporal, desde que se entenda a atividade mimética antropologicamente, como uma tentativa do homem de conquistar o tempo numa outra dimensão, a semiótica, de vencer seus abismos hiantes e controlar seu fluxo inexorável pela razão.

Já na antiga Grécia, a relação estreita entre tempo histórico e narrativa é equacionada por Aristóteles, quando, em sua Poética, ele afirma ser a poesia mais filosófica e nobre que a crônica histórica porque esta deve representar o que aconteceu, todos os acontecimentos de uma época, sem que neles se percebam as ligações causais que thes conferem unidade, atendo-se ao particular, enquanto aquela, através da poiésis, representa o que poderia acontecer, seleciona esses possíveis e

3 SANTO AGOSTINHO. Confissöes. Livro 11. 
ordena-os num todo proporcional, regido pela necessidade e a verossimilhança, revelando neles o geral (capitulos 8 e 9).

Percebe-se no pensamento de Aristóteles uma concepção da ciência da história como um dever para com o real, não modificável ao arbítrio do historiador, que pode narrar - inclusive em verso - mas não pode extrair falsamente dos acontecimentos ênfases, limites e efeitos e muito menos uma finalidade que não seja a de dar a conhecer tudo o que efetivamente se passou. Ao poeta, entretanto, ele liberta da constrição da veridicidade e da sujeição ao acaso. O possivel de acontecer ainda exige um vínculo com a probabilidade lógica de, dadas tais condições, uma consequiência determinada vir a ocorrer, mas o poeta tem uma margem muito maior de ação. As coisas na poesia devem ser representadas como são, como eram, como parecem ser, como devem ser, ou como os outros dizem que são (Capítulo 25), o que definitivamente subverte a noção de objetividade e institui a mente ou a comunidade como instâncias decisórias para a verossimilhança.

Dessa raiz antropológica original, deriva a potência da mímese de essencializar o tempo histórico, organizando na estrutura do mithos - unitário, ordenado, de certa grandeza - a sorte humana e concedendo-lhe compreensibilidade. Esse efeito, obtido pelo arranjo sistemático dos fatos, se dá efetuando a mutação da fortuna no nó, pela hamartia, e levando ao reconhecimento das conseqüências desta, por peripécias, no desenlace (Capítulo 18). Todo esse processo afeta as emoções do espectador ou ouvinte, suscita-as e leva-as à expressão, purgando-as, de modo que no final da experiência poética ele enfrenta o infortúnio mimetizado com serenidade, reflexão e se torna potencialmente capaz de fazer o mesmo na vida prática, deixando de ser regido, nesta, pelas paixões. ${ }^{4}$

Está aí a diferença fundamental entre o tratamento da história pela narrativa do historiador e do poeta. Na perspectiva de Aristóteles, o primeiro registra e infor$\mathrm{ma}$, apelando para o entendimento intelectual, que deve efetuar as ligações causais entre os acontecimentos apenas quando isso for possivel e ficando entregue aos dilemas da vida, quando não o for, enquanto o segundo explora possibilidades inventivamente e esclarece sem anular as sensações e emoções. Evidentemente, o Estagirita ignora que a dinâmica da narratividade impõe, mesmo a essa figura de historiador totalmente objetivo, a manipulação dos fatos e o desejo de produzir efeitos persuasivos, mas acerta quando requer do poeta que se liberte do vivido e explore os possiveis narrativos dentro do sistema da história contada e não do caos da história puramente vivida.

Dessa exposição, é possivel deduzir que a noção de tempo, entre os gregos, rege-se pela linearidade cronológica, mas admite os momentos de revelação, as epifanias, em que o fluxo temporal como que se detém, para abrir-se ao não-tempo, ao sagrado. Na epopéia, essa linearidade é preenchida por eventos concretos, apresentados sucessivamente com toda a sua riqueza de elementos e a apreensão psicológica da significação destes para o herói vem na voz do narrador distanciado do épico. A mutação da sorte se dá mais explicitamente pela intervenção dos deuses que pela vontade humana, que eles manipulam. Vejam-se esses fragmentos

4 ARISTÓTELES. Poétique. Trad. par Roselyne Dupont-Roc et Jean Lallot. Paris: Seuil, 1980. 
das rapsódias 23 e 24 da Ilíada, referentes ao enterro de Pátroclo e à profanação do cadáver de Heitor por Aquiles:

" $\mathrm{E}$ os ventos correram afugentando diante de si as nuvens; e maravilhoso era o modo como eles assobiavam; e sopraram sobre o mar, e o mar atirou-se para as nuvens; chegados à região de Tróia sibilaram com mais força: redemoinharam as folhas, remorejou o arvoredo, cantou o canavial. E perto da praia, um de um lado, outro de outro, sopraram com quanta força tinham. O lume sopitado dentro da pilha principiou logo a ronronar e, quase logo, uma grande flama saltou no ar e, por milagre, deu um grande ronco. E Bóreas e Zéfiros juntos toda a noite sopraram à fogueira com o hálito sibilante; e toda a noite o desembaraçado Aquileus encharcava o chão de vinho que tirava copo a copo de uma talha de ouro e sem cessar invocava a alma do infeliz Pátroclos. Como chora um pai ao queimar os ossos de filho que lhe morreu novo e casado de há pouco, assim Aquileus se atarefava na queima do companheiro, rodeando a fogueira e soltando gemidos lúgubres." (p. 64)

"E quanto mais denso era o recordar, mais fundo o pungiam as mágoas; tanto que, para escorrer da triste figura o pranto, se levantou e correu sem saber para onde. Até ao romper da aurora divagou ao acaso, quase sem tino, ao longo da praia, ora subindo as ribas fragosas, ora parando junto às vagas rumorosas.

"E quando chegou a luz do dia, já naquelas negras e cruéis mágoas se havia gerado bárbaro e cruel desatino: Aquileus atrelou os cavalos, atou ao carro o cadáver de Heitor e deu três voltas ao túmulo de Pátroclos. Feito isso, deixou o cadáver de rosto no chão, e se recolheu na barraca, estúpido e inerte. Apolão, entretanto, tornou a pele do cadáver resistente, ilacerável, inatingível aos ultrajes, porque o deus apiedou-se deste homem morto, e lhe envolveu todo o corpo de sua égide de ouro, para Aquileus não o poder despedaçar, arrastando-o" (p. 94). ${ }^{5}$

Nesses trechos nota-se que os eventos são alinhados um após o outro, na ordem rigorosamente cronológica, mas a mudança de sorte se dá pela epifania dos deuses. Bóreas e Zéfiros só sopram para queimar a pira fúnebre e completar as exéquias de Pátroclo por intervenção de Íris. Sem isso, a narrativa não poderia prosseguir e se deteria no eterno presente da pira que não queima. Os sentimentos de Aquiles não são sentidos, na perspectiva abstrata da consciência, mas descritos de fora pelo narrador onisciente, com uma evidência concreta: Aquiles age para mostrá-los. O ultraje a Heitor - obra humana da fúria de Aquiles, que o cega para o dever do respeito aos mortos - levará os deuses a impedir que ele cumpra a ameaça de entregar os restos aos cães e Príamo resgatará o corpo por graça de Hermes. Nada parece mudar, pois, nesse tempo heróico, se o sagrado não o aciona. Homero, entretanto, já introduz a força da vontade humana como motriz da história, anterior às providências divinas. Nada disso aconteceria se Aquiles não se enfurecesse, impelido pelos sentimentos da honra e da amizade. Com isso, as epifanias sagradas perdem seu papel mítico primordial e se inaugura a narrativa poética, ou seja, aquela em que a determinação temporal não interessa e sim a determinação lógica.

Como quer Aristóteles, o poeta Homero arranja os fatos legados pela lenda sobre o funeral de Pátroclo pondo no centro da cena a ação de Aquiles, determinada

5 HOMERO. Míada. Trad. do Pe. M. Alves Correia. Lisboa: Sá da Costa, 1944. 
por seu caráter desmedido e contrasta esse plano humano às maquinações divinas, destituindo-as da sua força primitiva. O ouvinte das rapsódias será empolgado pelo ritmo da narração, pelo caudal de detalhes dos acontecimentos, pela potência das medidas divinas, mas, pelo arranjo necessário das ações, perceberá a impropriedade do enfurecimento do herói, sem deixar de admirar sua lealdade ao amigo morto. Um tempo humano, assim, substitui o tempo sagrado, circular, da narrativa mítica. Aquiles, a cada decisão, constrói a sua vida e o fato de que a Natureza, personificada nos deuses menores e as divindades olímpicas se erguem ora a favor ora contra ele, propondo peripécias para que chegue ao desenlace de seu erro, não impede que essa vida se encaminhe para um final que ele - e não os deuses - escolheu e que o dignifica aos olhos do público.

Retomando essa visão aristotélica na contemporaneidade, Paul Ricoeur a entende como um esforço para produzir-se poeticamente a concorđância sobre a discordância fundamental do vivido. Essa concordância se opera pelo agenciamento dos elementos na estrutura da história mimética. Diz Ricoeur que "o mithos trágico se eleva como a solução poética do paradoxo especulativo do tempo, na medida mesma em que a invenção da ordem substitui a exclusão de toda característica temporal" (p. 65). ${ }^{6}$ Para Ricoeur, a sucessão cronológica do tempo físico ou do tempo vivido, prenhe de incoerências, na narrativa é submetida a uma ordem lógica, oriunda da composição, a qual "não salienta apenas a concordância, mas, de modo muito sutil, o jogo da discordância no interior da concordância" (p. 65). Ou seja, a história mimética não apenas re-apresenta os atos humanos num determinado espaço-tempo, mas dá a esse espaço-tempo um limite arbitrário- ele deve começar e terminar em certos lugares e tudo o que nele houver terá essas fronteiras como antecedentes e conseqüentes - e a esses atos um encadeamento necessário de antecedência e conseqüência que compõe, artificialmente, um todo uno e ordenado.

Todavia, nessa unidade composta, poiética, as mudanças de rumo da ação e a mudança de fortuna do herói, embora pertencentes a esse arranjo lógico, são ao mesmo tempo a sua ameaça de desmoronamento. As peripécias, os reconhecimentos e as catástrofes atuam na estruturação desse todo como seus motores, mas sua Natureza é paradoxal, criando tensão entre acaso e necessidade. Se a narrativa sempre versa sobre a reversão de um destino, se é preciso buscar, pela mímese, um sentido no não-sentido da existência mimetizada, substituindo a perplexidade ante o inesperado pela lucidez que o incorpora a um esquema inteligivel, a obrigação da narrativa é tornar necessários esses elementos paradoxais do vivido.

Vê-se, nessa posição de Ricoeur, que a noção moderna de tempo já não é a mesma que a vigente à época de Aristóteles. Aqui o tempo não se subordina à linearidade do fluxo, admite a incoerência entre um momento e outro e, portanto, sua descontinuidade e multiplanearidade. Porém, tal como Aristóteles, Ricoeur também considera a narrativa como uma espécie de dominação do turbilhonar dos momentos evasivos.

Sem poder escapar dos avanços da narratologia na definição da estrutura da narrativa - os quais coincidem, é verdade que com maior sofisticação, com os postulados aristotélicos sobre o mithos - tenta pensar o lugar do incompreensivel nes-

6 RICOEUR, Paul. Temps et récit. Paris: Seuil 1983. v. 1. 
sa estrutura, admitindo que o tempo supera, como categoria, as possibilidades de sua representação pela história. Não é que dê à temporalidade um estatuto idealista, como faz Bergson com a noção de duração, mas indaga de uma perspectiva ético-prática qual a capacidade da narrativa de humanizar essa categoria que se impõe à consciência organizando-a como fluxo ao mesmo tempo que por ela é construida.

No âmbito da narrativa literária moderna, as aporias do tempo vivido e do tempo físico, das faculdades constitutivas da noção de tempo em relação às injunções do tempo real, natural, foram a pedra de toque de um sem número de obras, do romance ao drama. A discussão de dicotomias como poesia e verdade, tempo da consciência e tempo físico, história e ficção, vem desde os românticos, mas passa sempre pela constatação final de que a literatura é mais "filosófica", pois permite carregar de significação a existência, a qual só se constitui sob o tempo, e sob um tempo sentido como impermanência e finitude.

$\mathrm{Na}$ modernidade, a angústia da experiência interna e externa do tempo e a necessidade de representá-la com algum sentido, irá provocar técnicas de narração inovadoras em relação ao modelo originado da épica, para figurar os estados de consciência justapostos, caóticos ou fragmentários, bem como para acentuar aquilo que Ricoeur chama de "concordância discordante" na estruturação da narrativa.

Numa proposição do formalista russo Boris Tomachevski, cumpre distinguir na forma narrativa o enredo da fábula, correspondendo esta ao que é narrado e aquele ao modo como isso é narrado. A fábula corresponde à composição dos atos aristotélica, com nó e desenlace, que o formalista denomina dialeticamente de momentos de equilíbrio, desequilíbrio e novo equilíbrio através de peripécias, mas a trama decorre dos procedimentos artísticos de figuração disso numa ordem não mais causal, mas estética. Dos efeitos da trama o mais importante é a deformação do vivido, sua representação violentando o hábito perceptivo, de modo a forçar o consumidor a rever o real que serve de matéria ao narrado. ${ }^{7}$ Dá-se, assim, à narrativa literária, em contraste com as demais, a função social de despertar o estranhamento, de modo a que as vivências do tempo histórico sejam revistas para além do hábito cotidiano e - numa extensão da teoria - dos interesses ideológicos falsificadores de seu ser em si.

Tome-se como exemplo do tratamento temporal na narrativa moderna esses fragmentos do romance de James Joyce, Ulisses:

"O senhor Bloom entrou e sentou no lugar vago. Puxou a porta após si e bateu-a firme que fechasse firme. Atravessou um braço pela alça e mirou com seriedade pela janela aberta da carruagem para as cortinas abaixadas da avenida. Uma suspensa ao lado: uma velhinha espiando. Nariz alviachatado contra a vidraça. Agradecendo à sua estrela haver sido poupada ainda. Extraordinário o interesse que tomam por um cadáver. Alegres de nos ver partir damos-lhes tamanho trabalho chegando. A tarefa parece convir-lhes. Pisque-dizque pelas esquinas. Pisar perto em pontinhas de pé de medo que desperte. Então é deixá-lo pronto. Aviá-lo. Molly e a senhora Fleming preparando a cama. Puxe-o mais para o seu lado. Nossa

7 Cf. TOMACHEVSKI, B. "Temática". In: EIKHENBAUM et al. Teoria da literatura: formalistas russos. Porto Alegre: Globo, 1971. 
mortalha. Nunca se sabe quem te aviará morto. Lavar e pentear. Creio que lhes cortam unhas e cabelos. Guardam um tico num envelope. Crescem do mesmo modo depois. Tarefa suja. (p. 98)

"...Terra parda, úmida, começava a ser vista no buraco. Ela subia. Quase ao nível. Um monte de padas úmidas subia mais e mais, e os coveiros descansaram suas pás. Todos descobriram-se de novo por uns poucos instantes. O garoto arrimou sua coroa contra um canto: o cunhado a sua contra um montícolo. Os coveiros puseram seus bonés e carregaram suas pás terrosas para a carreta. Então bateram de leve as lâminas contra a grama: limpas. Um inclinou-se para arrancar do cabo um tufo longo de erva. Outro, deixando seus companheiros, prosseguiu lentamente ombro-arma, sua lâmina azulverberando. Silenciosamente, à capititumba, outro enrolava a faixa do caixão. Seu umbilicordão. O cunhado, retirando-se, colocou algo em sua mão livre. Agradecimentos em silêncio. Lamento, senhor: incomodar-se. Cabusmeneios. Sei o que é isso. Para vocês apenas" (p.128). ${ }^{8}$

Pode-se notar aqui que a notação dos momentos temporais segue duas claves. A seqüência de acontecimentos é a de um enterro, a que comparecem os amigos do falecido, entre eles Leopold Bloom. No primeiro fragmento, destaca-se a focalização do cortejo fúnebre feita a partir da consciência de Bloom, permeando cada evento do percurso com associações provocadas por vivências simultâneas: a velha espiando, o preparo dos corpos, Molly e a Sra. Fleming preparando o cadáver do filho morto dos Bloom, a persistência do crescimento dos cabelos e unhas. Todas essas outras vivências não são apresentadas seja na ordem cronológica em que ocorreram, seja na sua qualidade objetiva de fatos históricos ou de saberes populares. A atitude enojada de Bloom ante os fatos menos nobres da vida, tais como o fascínio pelos mortos, a decomposição tentando ser atacada pela higienização do defunto, e a dor inconfessada pela perda do filho menino impregnam a cena de notas chocantes, que se somam à justaposição associativa desdobrada em etapas pelo fluxo de consciência do protagonista.

No segundo fragmento, está-se de novo no modelo de narração épica. Há um narrador que poderia estar narrando ainda pelo foco de Bloom, mas já não faz associações nem é pessoal. Seja quem for que fala, distanciou-se e tornou-se onisciente. À diferença do narrador épico, não oferece o ato na plenitude de suas determinações. Seleciona e economiza os detalhes: do enterro salientam-se as pás, as coroas, o pagamento, mas não os sentimentos dos presentes. O enterro é mais um trabalho remunerado do que outra coisa. Além disso, a deformação se efetua aqui não apenas por essa economia doméstica mas pelos neologismos inesperados num contexto tão claramente realista e antipoético. A liberação dos poderes criativos da linguagem, nesse momento da narração, é singularizante e descondiciona mais uma vez a visão do leitor.

Como bem anota Ricoeur, nesses trechos, no jogo entre fábula e trama, a partir de um ângulo extremamente seletivo da narração, seja ela oriunda da consciência de Bloom ou do olhar sagaz para a mercantilização da morte do narrador onisciente, promove-se uma concordância de claro contorno estético, numa matéria

8 JOYCE, James. Ulisses. Trad. de Antônio Houaiss. Rio de Janeiro: Civilização Brasileira, 1966. 
que, antes da composição dos atos, seriả uma experiência desafinada de elementos triviais solenizados lado a lado com associações densas banalizadas.

Assim, pode-se entender a narrativa como um sistema de signos que se estrutura sempre por uma ordenação antes lógica que cronológica, mas que não pode fugir ao Cronos, uma vez que, em primeiro lugar, é um discurso temporalizado pela sucessão das frases. Estas instituem quadros imaginativos, os quais por sua vez se sucedem, atuando uns sobre os outros na dependência das operações da memória, da fantasia e do desejo, as mesmas que constituem, para a consciência, a vivência de um tempo não físico, mas humano. Finalmente, dessa sucessão e inter-relação, constrói-se 0 universo narrativo, em que os estágios anteriores de constituição se fundem e são reordenados outra vez pela memória, fantasia e desejo, numa temporalidade oscilante, durativa.

Por outro lado, essa sucessão não é casual, ao sabor dos eventos naturais ou sociais, ou dos impulsos inconscientes. No seu âmago, ela evidencia uma ordenação coerente, em que cada momento se esclarece pela sua relação de convergência ou de divergência com os outros. É isso que se entende por sucessão causal, ou lógica da narrativa e é isso que a distingue da pura experiência temporal, não semiotizada. $O$ fato de que o que fica de uma narrativa não são as suas seqüências, mas um todo reconstruído eminentemente pelos interesses e o desejo, anula a temporalidade ao mesmo tempo que permanentemente a reinstitui, porque nessa reconstrução a consciência outra vez é fluxo e temporalidade. Dai se pode concluir que tempo e narrativa são congeniais e vivem em tensão. $O$ que a narrativa poiética faz é transferir essa tensão para a órbita das cogitações, aliviando-a. Pois não é isso que significa "narrar o possivel de acontecer"? 